\title{
Radiofrequency ablation of small renal masses as an alternative to nephron-sparing surgery: preliminary results
}

\author{
Milosz Jasinski1,2, Jerzy Siekieraํㄹ Piotr Chlosta ${ }^{3,4}$, Witold Mikolajczak ${ }^{1}$, Tomasz Drewa ${ }^{2,3}$ \\ 1Department of Urology, Institute of Oncology, Bydgoszcz, Poland \\ 2Department of Tissue Engineering, Nicolaus Copernicus University, Bydgoszcz, Poland \\ 3Department of Urology, Institute of Oncology, Kielce, Poland \\ 4 University of Humanites and Sciences, Faculty of Health, Kielce, Poland
}

Videosurgery and Other Miniinvasive Techniques 2011; 6 (4): 242-245

DOI: $10.5114 /$ wiitm.2011.26259

\begin{abstract}
Introduction: Radical endoscopic minimal-invasive treatment methods, such as thermal ablation, are sought as an alternative to standard radical surgical treatment of kidney neoplasms. We analysed patients who could be qualified for radical treatment due to T1a renal tumour.

Material and methods: Twenty-three patients out of 129 who underwent radiofrequency thermal ablation of kidney tumours in the years 2003-2010 were analysed. The inclusion criteria were age below 70 years, lack of major comorbidities (ASA score 1, 2), and competent contralateral kidney. In all cases tumour size was below $4 \mathrm{~cm}$. All patients were followed up with computed tomography (CT) and ultrasonography (USG) every 6 months for 3 years.

Results: In 20 patients kidney tumour was biopsied before radiofrequency ablation (RFA) and 10 of these biopsies were positive and revealed cancer. Six patients required additional treatment due to recurrence visible in CT - 3 with a positive biopsy result, 1 with negative and 2 without biopsy. Three of them were treated with a second session of RFA, 1 with radical nephrectomy and 2 with partial nephrectomy. No disease dissemination was observed and all patients who received additional treatment remain disease free.

Conclusions: The RFA can be safely used in selected patients with T1a tumour as an alternative to partial nephrectomy. Careful follow-up is required after thermal ablation and allows early detection and successful treatment of recurrences.
\end{abstract}

Key words: radiofrequency ablation, small renal masses, nephron-sparing surgery.

\section{Introduction}

Radiofrequency ablation (RFA) is a treatment method that utilizes radiofrequency alternating current to ablate tissue around the needle electrode. Over the last 10 years, this technique has been gaining popularity in several fields of oncological surgery [1-3]. The introduction of RFA into other fields of surgery has fuelled the interest to study its application in treatment of small renal masses (SRM), less than $4 \mathrm{~cm}$. Some controversies remain, however, regarding its oncological efficacy. The RFA is a minimally invasive therapeutic modality for renal tumours. It can be an alternative to nephrectomy in patients with single kidney, bilateral tumours, von Hippel-Lindau disease and in those with contraindications for surgery [4-6]. The aim of this paper is to present our experiences 
with application of RFA in patients who could be qualified for nephron-sparing surgery (NSS) due to T1a kidney tumours.

\section{Material and methods}

Twenty-three patients out of 129 who underwent RFA in the years 2003-2010 were retrospectively analysed. The inclusion criteria were age below 70 years, lack of major comorbidities (ASA score 1 or 2), and competent contralateral kidney (Table I). Tumours were qualified based on computed tomography $(\mathrm{CT})$ and all were staged as T1a (average size $2.6 \pm 0.5 \mathrm{~cm}$ ). Pre-treatment biopsy was performed. Ultrasound-guided RFA was performed using alternating current $(460 \mathrm{kHz})$ conducted directly to the tumour with a needle electrode. Patients were followed according to guidelines prepared for NSS.

Table I. Patients undergoing radiofrequency ablation (RFA) due to small renal masses

\begin{tabular}{|c|c|c|c|c|c|c|c|c|}
\hline No. & $\begin{array}{c}\text { Age } \\
\text { [years] }\end{array}$ & $\begin{array}{l}\text { ASA } \\
\text { score }\end{array}$ & $\begin{array}{c}\text { Initial } \\
\text { creatinine } \\
{[\mu \mathrm{mol} / \mathrm{l}]}\end{array}$ & $\begin{array}{l}\text { Tumour } \\
\text { size }[\mathrm{cm}]\end{array}$ & $\begin{array}{l}\text { Pre-treatment } \\
\text { biopsy }\end{array}$ & Re-treatment & Final histology & $\begin{array}{c}\text { Follow } \\
\text { up } \\
\text { [months] }\end{array}$ \\
\hline 1 & 60 & 2 & 84 & 2.0 & Indefinite & & & 70 \\
\hline 2 & 56 & 2 & 61 & 2.8 & Indefinite & & & 54 \\
\hline 3 & 56 & 2 & 65 & 2.0 & CRCC & Radical surgery & CRCC & 52 \\
\hline 4 & 50 & 1 & 99 & 2.5 & Indefinite & & & 50 \\
\hline 5 & 46 & 2 & 80 & 2.7 & Not assessed & & & 43 \\
\hline 6 & 52 & 2 & 45 & 3.4 & Indefinite & & & 40 \\
\hline 7 & 60 & 1 & 88 & 2.9 & Indefinite & & & 39 \\
\hline 8 & 60 & 2 & 53 & 2.5 & CRCC & & & 35 \\
\hline 9 & 60 & 2 & 72 & 4.0 & Indefinite & & & 29 \\
\hline 10 & 58 & 2 & 60 & 2.4 & CRCC & & & 28 \\
\hline 11 & 37 & 1 & 57 & 2.0 & CRCC & NSS & Necrosis & 26 \\
\hline 12 & 52 & 2 & 71 & 2.5 & CRCC & & & 17 \\
\hline 13 & 50 & 2 & 70 & 1.0 & cRCC & & & 16 \\
\hline 14 & 64 & 2 & 62 & 2.6 & CRCC & RFA & & 16 \\
\hline 15 & 62 & 2 & 67 & 3.0 & Not assessed & RFA & & 15 \\
\hline 16 & 63 & 2 & 71 & 3.0 & Indefinite & RFA & & 14 \\
\hline 17 & 68 & 2 & 77 & 1.8 & Indefinite & NSS & Oncocytoma & 13 \\
\hline 18 & 70 & 2 & 81 & 1.5 & Indefinite & & & 11 \\
\hline 19 & 64 & 2 & 70 & 3.4 & CRCC & & & 11 \\
\hline 20 & 62 & 2 & 62 & 4.0 & CRCC & & & 6 \\
\hline 21 & 55 & 2 & 74 & 2.5 & Not assessed & & & 6 \\
\hline 22 & 58 & 1 & 84 & 3.0 & Cancer cells & & & 6 \\
\hline 23 & 47 & 2 & 43 & 2.3 & Indefinite & & & 5 \\
\hline
\end{tabular}

CRCC - clear cell type renal carcinoma, NSS - nephron-sparing surgery 


\section{Results}

In 20 of 23 patients the tumour was successfully biopsied before RFA and 10 of these biopsies were positive and revealed cancer. Six patients required additional treatment due to recurrence visible in CT 3 with a positive biopsy result, 1 with negative and 2 without biopsy. Three of them were treated with a second session of RFA, 1 with radical nephrectomy and 2 with partial nephrectomy (Table I). No disease dissemination was observed and all patients who received additional treatment due to recurrence remain disease free. Average follow-up time was 2 years ( 5 months to 5.8 years).

\section{Discussion}

While RFA allows ablative success to be achieved, it requires acceptance of re-treatment necessity in a certain percentage of cases. Although the recurrence risk after RFA is higher in comparison to radical nephrectomy, early detection with an appropriate follow-up often allows successful treatment with an additional RFA session or partial nephrectomy. In certain cases radical nephrectomy is required. Most of the patients retain their kidney and remain disease free. In our experience, the recurrence risk did not influence the survival or progression rate.

It must also be stressed that RFA is a minimally invasive treatment which can even be performed under local anaesthesia and is connected with shorter hospital stay than NSS or even laparoscopic nephrectomy. Complications after RFA are less frequent and they are more often minor in comparison to surgical series $[4,7]$. These facts render RFA an attractive minimally invasive treatment for SRM, which can be offered instead of partial nephrectomy [4]. The study cohort was small because of specific inclusion criteria - such patients should, according to guidelines, undergo NSS, while RFA is mainly recommended for older ones with serious comorbidities.

An important issue to be resolved is an informative and appropriately performed renal tumour biopsy (RTB). The RTBs gained popularity in the evaluation of SRM because imaging alone is insufficient to assess the underlying tumour aggressiveness. The complication rate was low, and neoplasm seeding along the needle track has been reported to be extremely rare [8]. A certain disadvantage of RTB is a considerable, although improving over time, per- centage of 'indefinite' biopsy results. The RTB is recommended to help differentiating benign from malignant SRM prior or during ablative therapies and in follow-up, especially after RFA [6-8].

The RFA was planned based on computed tomography examination prior to treatment while the procedure itself was performed under USG guidance. Effectiveness of US-guided RFA is reported to be comparable with CT-guided RFA results [9]. The RFA is safe and effective in renal tumours; corticomedullary lesions and tumours $>3 \mathrm{~cm}$, however, are associated with an increased probability of incomplete ablation. In tumours $>5 \mathrm{~cm}$, RFA has a significant failure rate [7]. The RFA provided successful treatment of SRM with a low recurrence rate as well as prolonged metastasis-free and cancer-specific survival rates at 5 years after treatment [5].

\section{Conclusions}

It seems that RFA can be safely performed in selected patients with T1a tumour as an alternative to partial nephrectomy. The tumour should be biopsied prior to RFA. Careful follow-up, similar to the one after NSS, is required after thermal ablation and allows early detection and successful treatment of recurrences.

\section{References}

1. Soukup B, Bismohun S, Reefy S, Mokbel K. The evolving role of radiofrequency ablation therapy of breast lesions. Anticancer Res 2010; 30: 3693-7.

2. Hublet A, Wijtenburg E, Lismonde M, et al. Feasibility of percutaneous radiofrequency ablation for pulmonary malignancies in the hands of the surgeon. Acta Chir Belg 2010; 110: 267-71.

3. Jaworski M, Rowiński O, Cieszanowski A, et al. Percutaneous radiofrequency ablation combined with chemoembolization in hepatocellular carcinoma: assessment of palliative treatment. Videosurgery and Other Miniinvasive Techniques 2009; 4: 59-66.

4. Joniau S, Tailly T, Goeman L, et al. Kidney radiofrequency ablation for small renal tumors: oncologic efficacy. J Endourol 2010; 24: 721-8.

5. Tracy CR, Raman JD, Donnally C, et al. Durable oncologic outcomes after radiofrequency ablation: experience from treating 243 small renal masses over 7.5 years. Cancer 2010; 116: 3135-42.

6. Hiraoka K, Kawauchi A, Nakamura T, et al. Radiofrequency ablation for renal tumors: our experience. Int J Urol 2009; 16: 869-73.

7. del Cura JL, Zabala R, Iriarte J, Unda M. Treatment of renal tumors by percutaneous ultrasound-guided radiofrequency ablation using a multitined electrode: effectiveness and complications. Eur Urol 2010; 57: 459-65. 
8. Samplaski MK, Zhou M, Lane BR, et al. Renal mass sampling: an enlightened perspective. Int J Urol 2011; 18: 5-19.

9. Davis K, Kielar A, Jafari K. Effectiveness of ultrasound-guided radiofrequency ablation in the treatment of 36 renal cell carcinoma tumours compared with published results of using computed tomography guidance. Can Assoc Radiol J 2010 Dec 7. [Epub ahead of print]. DOI: 10.1016/j.carj.2010.09.008. 